\title{
Human Resource Manager Selection Based on Logarithmic Fuzzy Preference Programming and TOPSIS Methods
}

\author{
Seyed Reza Seyed Javadein \\ Professor, Department of Management, University of Tehran, Tehran, Iran \\ Mohammad Reza Fathi \\ PhD Candidate of Industrial Management, University of Tehran, Tehran, Iran
}

\author{
Amirhesam Behrooz \\ M.S. Candidate of Executive Management of Business Administration, University of \\ Tehran, Tehran, Iran \\ Mohammad Reza Sadeghi (Corresponding Author) \\ M.S. of public Administration, University of Tehran, Tehran, Iran
}

Accepted: March 03, 2013 Published: May 09, 2013

Doi:10.5296/ijhrs.v3i2.3591

URL: http://dx.doi.org/10.5296/ijhrs.v3i2.3591

\begin{abstract}
Today's organizations must gain competitive advantage through the effective utilization of their human resources. Successful human resource management can contribute to superior performance as a source of competitive advantage by making organizations more effective. The purpose of this paper is applying a new integrated method to Human Resource Manager Selection. Proposed approach is based on Logarithmic fuzzy preference programming and TOPSIS methods. LFPP method is used in determining the weights of the criteria by decision makers and then selecting Human Resource Manager are determined by TOPSIS method. A real case demonstrates the application of the proposed method.
\end{abstract}

Keywords: Human resource manager, Logarithmic fuzzy preference programming (LFPP), Fuzzy set, TOPSIS

\section{Introduction}

Human Resource Management, like many other aspects of management, was originally conceptualized and developed in the United States of America (Brewster, 2004). The notion of Human Resource Management (HRM) as an ideological framework to effectively and 
efficiently manage labor took root as an academic theory, a practitioner's tool kit and a managerial profession in the late 1970s in Europe and Australasia (Beardwell, Holden, \& Claydon, 2004). Ferris, Hall, Royle, and Martocchio (2004) suggest that in the USA the term has been used to describe labor management practices since the early part of the $20^{\text {th }}$ century, but the finer distinctions between personnel management and HRM as a popular, descriptive label are not the concern here (Marlow, 2006). Because of the ever-increasing international competition, aggressive mergers and acquisitions, high-speed e-communication, and rapid technological advances, along with demographic and social changes, HR practitioners have new roles to play (Brewster, Farndale, \& van Ommeren, 2000; Lipiec, 2001). It has been projected that HR's role will completely change within a decade (Selmer \& Chiu, 2004). Previously, competency was defined as the fundamental abilities and capabilities that an employee should have in order to do a job well (Furnham, 1990) or one's characteristics that can differentiate significantly between effective and ineffective performance (Spencer, McClelland, \& Spencer, 1990). The concept of competency can be viewed differently within an organization. From a strategic management perspective, Hitt, Ireland, and Hoskisson (2005) define competencies as a combination of resources and capabilities. The combination of resources and capabilities in an organization can be classified as core competencies when they are valuable, rare, difficult to imitate, and difficult to substitute (Cardy \& Selvarajan, 2006). In general, competency is defined as a person related concept referring to a set of dimensions of behavior constituting one's superior performance at work (Mansfield, 1999; Woodruffe, 1991). Nowadays, competencies are used in many facets of human resource management, ranging from individual functions like recruitment and performance management to organizational strategic planning, such as design of organizational structure and culture (Selmer \& Chiu, 2004). The concept of the management competencies originates from Dale and Iles (1992). These competencies are considered behavioral, and specify the skills "required" of a person in a specific task (Sudsakorn \& Swierczek, 2009). Boyatzis (1982) defined managerial competencies as the individual's characteristics that are causally related to effective and/or superior job performance of managers. For these characteristics to be recognized as competencies they must differentiate superior performance from average and poor performance (Chong, 2008). The competency model is a set of competencies, namely success factors which include the key behaviors required for excellent performance in a particular role (Schoonover et al., 2000, as cited in Wu \& Lee, 2007). There are several useful manager competency models, such as: Boyatzis (1982), Hellriegel, Jackson, and Slocum (2002), Quinn, Faerman, Thompson, and McGrath (1996), and Spencer and Spencer (1993). However, each of these competency models contains too many competencies. It is hard for someone to master a broad set of competencies simultaneously. In order to be smart for launching competency applications effectively, it is a favorable way that focusing on some urgent competencies and implementing them with a stepwise mode ( $\mathrm{Wu}$, Lee, \& Tzeng, 2005, as cited in Wu \& Lee, 2007). In their book chapter on the role of competency in developing organizational competitiveness, Turner and Crawford (1994) broadly classify competencies as belonging to one of two categories: personal or corporate. Personal competencies are possessed by individuals and include characteristics such as knowledge, skills, abilities, experience, and personality. Corporate competencies belong to the 
organization and are embedded processes and structures that tend to reside within the organization, even when individuals leave. These two categories are not entirely independent (Cardy \& Selvarajan, 2006).

In theory, HRM practices shape firm performance through three key channels. As related by Huselid (1995), HRM practices:

(1) Increase employees' knowledge, skills, and abilities (KSAs);

(2) Motivate employees to leverage their KSAs for the firm's benefit; and

(3) Empower employees to do so (Liu et al., 2007).

Competencies have been identified and competency models developed from differing sources or perspectives. Perhaps the dominant model to date is the development and reliance on generic competencies. The fundamental assumption behind generic competencies is that a set of characteristics necessary for success across organizational settings can be identified. For example, Thornton and Byham (1982) identified a list of competencies for top management that includes leadership skills, general management skills, interpersonal skills, communication skills, creativity, and personality traits such as dependability and adaptability. Dulewicz (1989) identified a set of four clusters of competencies as important for middle managers. The four middle manager competency clusters include those categorized as:

1. Intellectual (e.g., strategic perspective, analysis, and judgments)

2. Interpersonal (e.g., persuasiveness, decisiveness)

3. Adaptability (e.g., resilience)

4. Results orientation (e.g., initiative, business sense) (Cardy \& Selvarajan, 2006).

Thus, Selection of the most qualified human resource manager is a key success factor for an organization. Traditionally, a human resource manager is selected by interviewing applicants and considering their qualifications and the organization requirements. The interviews are usually conducted by top managers. In every human decision, there is the possibility of an error in judgment, so the results may not be dependable. Thus, there is a need for a method that can select the most suitable and most qualified applicant for the post of human resource manager, given his/her capabilities and the top managers' opinions. In this paper, the Logarithmic Fuzzy Preference Programming and TOPSIS are used to conduct a case study of HR manager selection procedure in Pars Tire Company. The remainder of this paper is organized as follows. Fuzzy sets and Fuzzy numbers are briefly explained in Section 2. Then in Section 3, LFPP and TOPSIS methods are introduced. In Section 4, the application of proposed methods is illustrated and finally, conclusion is provided in Section 5.

\section{Fuzzy set theory}

Fuzzy set theory was first developed in 1965 by Zadeh; he was attempting to solve fuzzy phenomenon problems, including problems with uncertain, incomplete, unspecific, or fuzzy situations. Fuzzy set theory is more advantageous than traditional set theory when describing set concepts in human language. It allows us to address unspecific and fuzzy characteristics by using a membership function that partitions a fuzzy set into subsets of members that "incompletely belong to" or "incompletely do not belong to" a given subset. 


\subsection{Fuzzy Numbers}

2013, Vol. 3, No. 2

We order the Universe of Discourse such that $U$ is a collection of targets, where each target in the Universe of Discourse is called an element. Fuzzy number $\widetilde{\mathrm{A}}$ is mapped onto U such that a random $\mathrm{x} \rightarrow \mathrm{U}$ is appointed a real number, $\mu_{\tilde{\mathbb{A}}}(\mathrm{x}) \rightarrow[0,1]$. If another element in $\mathrm{U}$ is greater than $\mathrm{x}$, we call that element under A.

The universe of real numbers $R$ is a triangular fuzzy number (TFN) $\widetilde{A}$, which means that for $\mathrm{x} \in \mathrm{R}, \mu_{\tilde{\mathrm{A}}}(\mathrm{x}) \in[0,1]$, and

$$
\mu_{\tilde{A}}(\mathrm{x})=\left\{\begin{array}{rr}
(\mathrm{x}-\mathrm{L}) /(\mathrm{M}-\mathrm{L}), & \mathrm{L} \leq \mathrm{x} \leq \mathrm{M}, \\
(\mathrm{U}-\mathrm{x}) /(\mathrm{U}-\mathrm{M}), & \mathrm{M} \leq \mathrm{x} \leq \mathrm{U}, \\
0, \text { otherwise, } &
\end{array}\right.
$$

Note that $\widetilde{\mathrm{A}}=(\mathrm{L}, \mathrm{M}, \mathrm{U})$, where $\mathrm{L}$ and $\mathrm{U}$ represent fuzzy probability between the lower and upper boundaries, respectively, as in Fig. 1. Assume two fuzzy numbers $\widetilde{\mathrm{A}}_{1}=\left(\mathrm{L}_{1}, \mathrm{M}_{1}, \mathrm{U}_{1}\right)$, and $\widetilde{\mathrm{A}}_{2}=\left(\mathrm{L}_{2}, \mathrm{M}_{2}, \mathrm{U}_{2}\right) ;$ then,

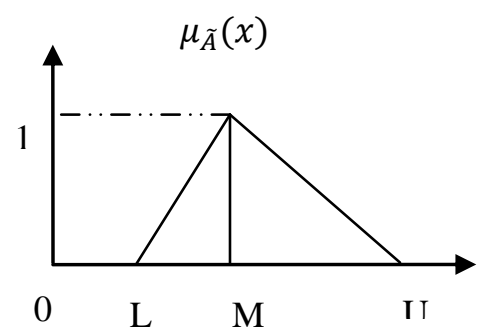

Fig. 1: Triangular fuzzy number

(1) $\widetilde{\mathrm{A}}_{1} \oplus \widetilde{\mathrm{A}}_{2}=\left(\mathrm{L}_{1}, \mathrm{M}_{1}, \mathrm{U}_{1}\right) \oplus\left(\mathrm{L}_{2}, \mathrm{M}_{2}, \mathrm{U}_{2}\right)=\left(\mathrm{L}_{1}+\mathrm{L}_{2}, \mathrm{M}_{1}+\mathrm{M}_{2}, \mathrm{U}_{1}+\mathrm{U}_{2}\right)$

(2) $\widetilde{\mathrm{A}}_{1} \otimes \widetilde{\mathrm{A}}_{2}=\left(\mathrm{L}_{1}, \mathrm{M}_{1}, \mathrm{U}_{1}\right) \otimes\left(\mathrm{L}_{2}, \mathrm{M}_{2}, \mathrm{U}_{2}\right)=\left(\mathrm{L}_{1} \mathrm{~L}_{2}, \mathrm{M}_{1} \mathrm{M}_{2}, \mathrm{U}_{1} \mathrm{U}_{2}\right), \mathrm{L}_{\mathrm{i}}>0, \mathrm{M}_{\mathrm{i}}>0, \mathrm{U}_{\mathrm{i}}>0$

(3) $\widetilde{\mathrm{A}}_{1}-\widetilde{\mathrm{A}}_{2}=\left(\mathrm{L}_{1}, \mathrm{M}_{1}, \mathrm{U}_{1}\right)-\left(\mathrm{L}_{2}, \mathrm{M}_{2}, \mathrm{U}_{2}\right)=\left(\mathrm{L}_{1}-\mathrm{L}_{2}, \mathrm{M}_{1}-\mathrm{M}_{2}, \mathrm{U}_{1}-\mathrm{U}_{2}\right)$ 
(4) $\widetilde{\mathrm{A}}_{1} \div \widetilde{\mathrm{A}}_{2}=\left(\mathrm{L}_{1}, \mathrm{M}_{1}, \mathrm{U}_{1}\right) \div\left(\mathrm{L}_{2}, \mathrm{M}_{2}, \mathrm{U}_{2}\right)=\left(\frac{\mathrm{L}_{1}}{\mathrm{~L}_{2}}, \frac{\mathrm{M}_{1}}{\mathrm{M}_{2}}, \frac{\mathrm{U}_{1}}{\mathrm{U}_{2}}\right), \mathrm{L}_{\mathrm{i}}>0, \mathrm{M}_{\mathrm{i}}>0, \mathrm{U}_{\mathrm{i}}>0$

(5) $\widetilde{\mathrm{A}}_{1}^{-1}=\left(\mathrm{L}_{1}, \mathrm{M}_{1}, \mathrm{U}_{1}\right)^{-1}=\left(\frac{1}{\mathrm{U}_{1}}, \frac{1}{\mathrm{M}_{1}}, \frac{1}{\mathrm{~L}_{1}}\right), \mathrm{L}_{\mathrm{i}}>0, \mathrm{M}_{\mathrm{i}}>0, \mathrm{U}_{\mathrm{i}}>0$

\subsection{Fuzzy Linguistic Variables}

The fuzzy linguistic variable is a variable that reflects different aspects of human language. Its value represents the range from natural to artificial language. When the values or meanings of a linguistic factor are being reflected, the resulting variable must also reflect appropriate modes of change for that linguistic factor. Moreover, variables describing a human word or sentence can be divided into numerous linguistic criteria, such as equally important, moderately important, strongly important, very strongly important, and extremely important. For the purposes of the present study, the 5-point scale (equally important, moderately important, strongly important, very strongly important and extremely important) is used.

\section{Research Methodology}

In this paper, the weights of each criterion are calculated using LFPP. After that, TOPSIS is utilized to rank the alternatives. Finally, we select the best person based on these results.

\subsection{The LFPP-based nonlinear priority method}

In this method for the fuzzy pairwise comparison matrix, Wang et al (2011) took its logarithm by the following approximate equation:

$\ln \tilde{a} \quad=\quad\left(\ln l_{i j} \quad, \quad \ln m_{i j} \quad, \quad \ln l u_{i j} \quad\right), \quad \mathrm{i}, \mathrm{j} \quad=\quad 1 \ldots, \mathrm{n}$

That is, the logarithm of a triangular fuzzy judgment $\mathrm{a}_{\mathrm{ij}}$ can still be seen as an approximate triangular fuzzy number, whose membership function can accordingly be defined as

$\mu_{i j}\left(\ln \left(\frac{w_{i}}{w_{j}}\right)\right)$

$$
\left\{\begin{array}{l}
\frac{\ln \left(\frac{w_{i}}{w_{j}}\right)-\ln l_{i j}}{\ln m_{i j}-\ln l_{i j}}, \ln \left(\frac{w_{i}}{w_{j}}\right) \leq \ln m_{i j}, \\
\frac{\ln w_{i j}-\ln \left(\frac{w_{i}}{w_{j}}\right)}{\ln w_{i j}-\ln m_{i j}}, \ln \left(\frac{w_{i}}{w_{j}}\right) \geq \ln m_{i j},
\end{array}\right\}
$$


Where $\mu_{i j}\left(\ln \left(\frac{w_{i}}{w_{j}}\right)\right)$ is the membership degree of $\ln \left(\frac{w_{i}}{w_{j}}\right)$ belonging to the approximate triangular fuzzy judgment $\ln \tilde{a}=\left(\ln l_{i j}, \ln m_{i j}, \ln l u_{i j}\right)$. It is very natural that we hope to find a crisp priority vector to maximize the minimum membership degree $\lambda=\min \left\{\mu_{i j}\left(\ln \left(\frac{w_{i}}{w_{j}}\right)\right)\right.$ $\mathrm{i}=1, \ldots, \mathrm{n}-1 ; \mathrm{j}=\mathrm{i}+1, \ldots, \mathrm{n}\}$. The resultant model can be constructed (Wang et al, 2011) as

Maximize $\lambda$

$$
\text { Subject } \quad \text { to } \quad\left\{\begin{array}{c}
\mu_{i j}\left(\ln \left(\frac{w_{i}}{w_{j}}\right)\right) \begin{array}{c}
\geq, i=1, \ldots, n-1 ; j=i+1, \ldots, n, \\
w_{i} \geq 0, i=1, \ldots, n,
\end{array}
\end{array}\right\}
$$

Or as

$$
\text { Maximize } \quad 1-\lambda
$$

Subject to $\left\{\begin{array}{l}\ln w_{i}-\ln w_{j}-\lambda \ln \left(\frac{m_{i j}}{l_{i j}}\right) \geq \ln l_{i j}, i=1, \ldots, n-1 ; j=i+1, \ldots, n, \\ -\ln w_{i}+\ln w_{j}-\lambda \ln \left(\frac{u_{i j}}{m_{i j}}\right) \geq-\ln u_{i j}, i=1, \ldots, n ; j=i+1, \ldots, n,\end{array}\right\}$

It is seen that the normalization constraint $\sum_{i=1}^{n} w_{i}=1$ is not included in the above two equivalent models. This is because the models will become computationally complicated if the normalization constraint is included. Before normalization, without loss of generality, we can assume $w_{i} \geq 1$ for all $i=1, \ldots, n$ such that $\ln w_{i} \geq 0$ for $i=1, \ldots, n$. Note that the nonnegative assumption for $\ln w_{i} \geq 0(\mathrm{i}=1, \ldots, \mathrm{n})$ is not essential. The reason for producing a negative value for $\lambda$ is that there are no weights that can meet all the fuzzy judgments in $\widetilde{A}$ within their support intervals. That is to say, not all the inequalities $\ln w_{i}-\ln w_{j}-\lambda \ln \left(\frac{m_{i j}}{I_{i j}}\right) \geq \ln l_{i j}$ or $-\ln w_{i}+\ln w_{j}-\lambda \ln \left(\frac{u_{i j}}{m_{i j}}\right) \geq-\ln u_{i j}$ can hold at the same time. To avoid k from taking a negative value, Wang et al (2011) introduced nonnegative deviation variables $\delta_{i j}$ and $\mathrm{n}_{i j}$ for $i=1, \ldots, n-1 ; j=i+1, \ldots, n$, such that they meet the following inequalities: 
$\ln w_{i}-\ln w_{j}-\lambda \ln \left(\frac{m_{i j}}{l_{i j}}\right) \geq \ln l_{i j}, i=1, \ldots, n-1 ; j=i+1, \ldots, n$

$-\ln w_{i}+\ln w_{j}-\lambda \ln \left(\frac{u_{i j}}{m_{i j}}\right) \geq-\ln u_{i j}, i=1, \ldots, n ; j=i+1, \ldots, n$

It is the most desirable that the values of the deviation variables are the smaller the better. Wang et al (2011) thus proposed the following LFPP-based nonlinear priority model for fuzzy AHP weight derivation:

Minimize

$$
\mathrm{J}=(1-\lambda)^{2}+\mathrm{M} \cdot \sum_{i=1}^{n-1} \sum_{j=i+1}^{n}\left(\delta_{i j}^{2}+\mathrm{n}_{i j}^{2}\right)
$$

Subject

$$
\left\{\begin{array}{c}
x_{i}-x_{j}-\lambda \ln \left(\frac{m_{i j}}{l_{i j}}\right)+\delta_{i j} \geq \ln l_{i j}, i=1, \ldots, n-1 ; j=i+1, \ldots, n, \\
-x_{i}+x_{j}-\lambda \ln \left(\frac{u_{i j}}{m_{i j}}\right)+\eta_{i j} \geq-\ln u_{i j}, i=1, \ldots, n ; j=i+1, \ldots, n, n, \\
\lambda, x_{i} \geq 0, i=1, \ldots, n \\
\delta_{i j}, \mathrm{1}_{i j} \geq 0, i=1, \ldots, n-1 ; j=i+1, \ldots, n
\end{array}\right\}
$$

Where $x_{i}=\ln w_{i}$ for $\mathrm{i}=1, \ldots, \mathrm{n}$ and $\mathrm{M}$ is a specified sufficiently large constant such as $\mathrm{M}=$

$10^{3}$. The main purpose of introducing a big constant $M$ into the above model is to find the weights within the support intervals of fuzzy judgments without violations or with as little violations as possible.

\subsection{The TOPSIS Method}

The TOPSIS method is proposed in Chen and Hwang (1992), with reference to Hwang and Yoon (1981). The basic principle is that the chosen alternative should have the shortest distance from the ideal solution that maximizes the benefit and also minimizes the total cost, and the farthest distance from the negative-ideal solution that minimizes the benefit and also maximizes the total cost (Opricovic and Tzeng, 2003). 


\section{Macrothink

The TOPSIS method consists of the following steps:

Step 1: Calculate the normalized decision matrix. The normalized value $\mathrm{r}_{\mathrm{ij}}$ is calculated as

$$
\mathrm{r}_{\mathrm{ij}}=X_{i j} / \sqrt{\sum_{\mathrm{i}=1}^{\mathrm{n}} X_{i j}^{2}}, \forall i, j
$$

Step 2: Calculate the weighted normalized decision matrix. The weighted normalized value $\mathrm{v}_{\mathrm{ij}}$ is calculated as

$$
\mathrm{v}_{\mathrm{i}} \quad \mathrm{j}=\quad \mathrm{w}_{\mathrm{j}} \mathrm{r}_{\mathrm{ij}},
$$

(13)

Where $\mathrm{w}_{\mathrm{j}}$ is the weight of the $j$ th criterion, and $\quad \sum_{\mathrm{i}=1}^{m} w_{j}=1$

Step 3: Determine the ideal and negative-ideal solution.
$\mathrm{A}^{*}$

$$
=
$$<smiles>[117In]</smiles>
$\left\{\left(\max _{i} v_{i j}\left[j \in C_{h h}\right),\left(\min _{i} v_{i j}\left[j \in C_{c}\right)\right\}\right.\right.$

where $C_{b}$ is associated with benefit criteria and $C_{c}$ is associated with cost criteria.

Step 4: Calculate the separation measures, using the m-dimensional Euclidean distance. The separation of each alternative from the ideal solution is given as

$$
S_{i}^{*}=\sqrt{\sum_{j=1}^{m}\left(v_{i j}-v_{j}^{*}\right)^{2}}
$$

Similarity, the separation from the negative-ideal solution is given as

$$
S_{i}^{-}=\sqrt{\sum_{j=1}^{m}\left(v_{i j}-v_{j}^{-}\right)^{2}}
$$

Step 5: Calculate the relative closeness to the ideal solution. The relative closeness of the alternative $A_{i}$ with respect to $A^{*}$ is defined as 
$R C_{l}^{*}=\frac{s_{i}^{-}}{s_{i}^{*}+s_{i}^{-}}, \forall i$

Step 6: Rank the preference order.

The index values of $R C_{l}^{*}$ lie between 0 and 1 . The larger index value means the closer to ideal solution for alternatives.

\section{Human Resource Manager selecting using integrated approach}

In this research, 12 experts and managers were invited to survey five alternatives using the research framework shown in Fig 2. Through the literature investigation and experts' opinions, the committee finally adopted 13 criteria. This research framework includes 13 evaluation criteria, such as Analytical thinking $\left(\mathrm{C}_{1}\right)$, Respect to others $\left(\mathrm{C}_{2}\right)$, Willingness $\left(\mathrm{C}_{3}\right)$, Responsibility $\left(\mathrm{C}_{4}\right)$, Appearance $\left(\mathrm{C}_{5}\right)$, Being competitiveness $\left(\mathrm{C}_{6}\right)$, Effective listening $\left(\mathrm{C}_{7}\right)$, Creativity $\left(\mathrm{C}_{8}\right)$, Foreign language $\left(\mathrm{C}_{9}\right)$, Principles of management $\left(\mathrm{C}_{10}\right)$, Organizational behavior $\left(\mathrm{C}_{11}\right)$, Change management $\left(\mathrm{C}_{12}\right)$ and Decision making $\left(\mathrm{C}_{13}\right)$. In addition, there are five alternatives include: person number one $\left(\mathrm{P}_{1}\right),\left(\mathrm{P}_{2}\right),\left(\mathrm{P}_{3}\right),\left(\mathrm{P}_{4}\right)$, and $\left(\mathrm{P}_{5}\right)$. For Selecting the Best Human Resource Manager, we used the research framework from Ghafarian (1999) and Zarei Matin et al (2011).

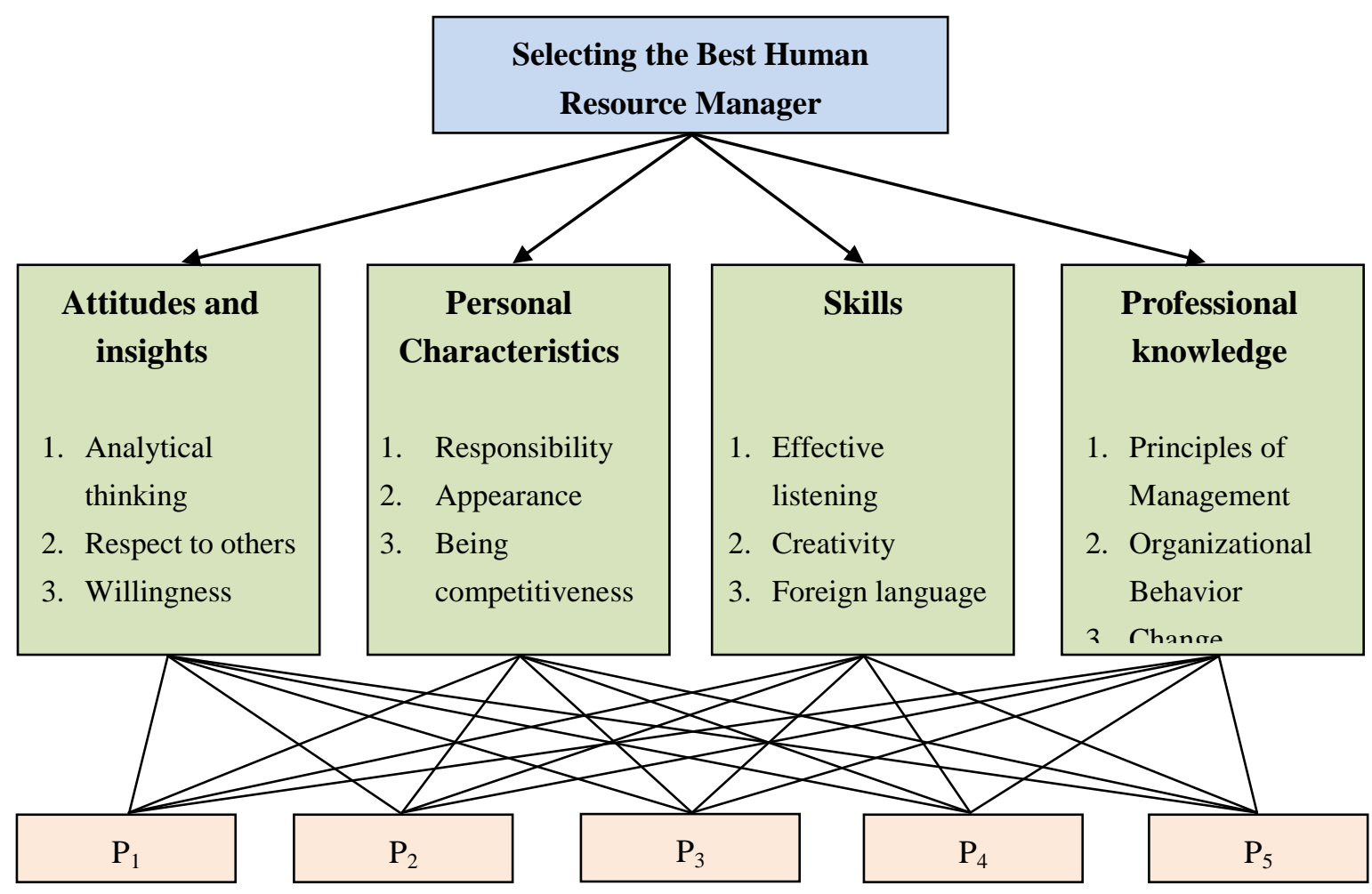


Fig 2: Research framework

In this paper, the weights of criteria are calculated by using LFPP, and these calculated weight values are used as TOPSIS inputs. Then, after TOPSIS calculations, evaluation of the alternatives and selection of Human Recourse Manger is realized.

\section{Logarithmic Fuzzy Preference Programming:}

In LFPP, firstly, we should determine the weights of each criterion by utilizing pair-wise comparison matrices. We compare each criterion with respect to other criteria. You can see the pair-wise comparison matrix for Professional knowledge criteria as an example in Table 1. The weights of other criteria are obtained like Professional knowledge criteria.

Table 1. Comparison matrix of Professional knowledge criteria

\begin{tabular}{|c|c|c|c|c|}
\hline & $C_{1}$ & $C_{2}$ & $C_{3}$ & $C_{4}$ \\
\hline$C_{1}$ & $(1.00,1.00,1.00)$ & $(3.00,4.00,5.00)$ & $(4.00,6.33,8.00)$ & $(0.2,1.80,5.00)$ \\
\hline$C_{2}$ & $(0.20,0.26,0.33)$ & $(1.00,1.00,1.00)$ & $(1.00,3.25,5.00)$ & $(0.14,0.83,2.00)$ \\
\hline$C_{3}$ & $(0.13,0.17,0.25)$ & $(0.20,0.51,1.00)$ & $(1.00,1.00,1.00)$ & $(0.20,1.18,3.00)$ \\
\hline$C_{4}$ & $(0.20,3.40,6.00)$ & $(0.50,2.83,5.00)$ & $(0.33,0.85,7.00)$ & $(1.00,1.00,1.00)$ \\
\hline
\end{tabular}

After forming the model (11) for the comparison matrix and solving this model using of Genetic algorithms, the weight vector is obtained as follow:

$w^{t}=(0.348166,0.147632,0.156035,0.348166)^{\mathrm{T}}$

After that evaluators were asked to build the decision matrix by comparing the alternatives under each criterion. In addition, the evaluators were asked to provide a set of crisp values within a range from 1 to 10 . By using Eqs. (12) and (13), the weighted normalized decision matrix calculated by multiplying the normalized decision matrix and the weights are obtained, as presented in Table 2 . 
Table 2: The weighted normalized decision matrix

\begin{tabular}{|c|c|c|c|c|c|c|}
\hline & C1 & C2 & C3 & $\ldots$ & C12 & C13 \\
\hline P1 & 0.80 & 0.83 & 0.57 & $\ldots$ & 0.71 & 0.92 \\
\hline P2 & 0.54 & 0.53 & 0.69 & $\ldots$ & 0.51 & 0.35 \\
\hline P3 & 0.07 & 0.07 & 0.13 & $\ldots$ & 0.32 & 0.16 \\
\hline P4 & -0.26 & -0.18 & 0.43 & $\ldots$ & 0.18 & 0.00 \\
\hline P5 & 0.01 & 0.01 & 0.01 & $\ldots$ & 0.31 & 0.11 \\
\hline
\end{tabular}

After developing the weighted normalized decision matrix, the final ranking procedure should determine the ideal solution and negative-ideal solutions by using Eqs. (14) and (15).

Table 3: Final ranking of persons

\begin{tabular}{|c|c|c|c|c|}
\hline & $\begin{array}{c}\text { Distance } \\
(+)\end{array}$ & $\begin{array}{c}\text { Distance } \\
(-)\end{array}$ & $\begin{array}{c}\text { Coefficient of } \\
\text { Colseness }\end{array}$ & ranking \\
\hline P1 & 0.09 & 0.19 & 0.69 & 1 \\
\hline P2 & 0.09 & 0.18 & 0.66 & 2 \\
\hline P3 & 0.13 & 0.18 & 0.58 & 3 \\
\hline P4 & 0.22 & 0.07 & 0.24 & 5 \\
\hline P5 & 0.14 & 0.15 & 0.53 & 4 \\
\hline
\end{tabular}

By using Eqs. (16) and (17), the computed distances of each person from ideal solution ( $\left.\mathrm{S}_{\mathrm{i}}^{*}\right)$

and negative-ideal solution $\left(\mathrm{S}_{\mathrm{i}}^{-}\right)$are presented in Table 3. Based on their relative closeness to the ideal solution obtained by using Eq. (18), the final step of the TOPSIS method consists of ranking HR managers. In this case, the results show that the alternative (P1) as the best choice and P2, P3, P5, P4 are the second, third fourth and Fifth choice.

\section{Conclusion}

Nowadays, Selection of the most qualified human resource manager is a key success factor for an organization. The complexity and importance of the problem call for analytical methods rather than Interviewing and intuitive decisions. In this paper, a two-step LFPP and TOPSIS methodology is structured here that TOPSIS uses LFPP result weights as input weights. Then a real case study is presented to show applicability and performance of the methodology. It can be said that using linguistic variables makes the evaluation process more realistic. Because evaluation is not an exact process and has fuzziness in its body. Here, the usage of LFPP weights in TOPSIS makes the application more realistic and reliable. The proposed model has only been implemented on a Human Resource selection problem. Finally, the results show that the alternative (P1) as the best choice and P2, P3, P5, P4 are the second, third fourth and Fifth choice. 
Acknowledgement

2013, Vol. 3, No. 2

The authors would like to thank the anonymous reviewers and the editor for their insightful comments and suggestions.

\section{References}

Beardwell, I., Holden, L., \& Claydon, T. (2004). Human resource management: A contemporary approach. London: FT Prentice Hall.

Boyatzis, R. E. (1982). The Competent Manager- A Model for Effective Performance. New York: John Wiley.

Brewster, C. (2004). European perspectives on human resource management. Human Resource Management Review, 14, 365-382.

Brewster, C., Farndale, E., \& van Ommeren, J. (2000). HR competencies and professional standards. UK, Cranfield: World Federation of Personnel Management Association.

Cardy, R. L., \& Selvarajan, T.T. ( 2006). Competencies: Alternative frameworks for competitive advantage. Business Horizons, 49, 235-245.

Chong, E. (2008). Managerial competency appraisal: A cross-cultural study of American and East Asian managers. Journal of Business Research, 61, 191-200.

Dale, M. and Iles, P. (1992), Assessing Management Skills: A Guide to Competencies and Evaluation Techniques, Kogan Page, London.

Dulewicz, V. (1989). Assessment centers as the route to competence. Personnel Management, 21(11), 56- 59 .

Ferris, G., Hall, A., Royle, M., \& Martocchio, J. (2004). Theoretical developments in the field of HRM: Issues and challenges for the future. Organizational Analysis, 12, 231-254.

Furnham, A. (1990). A question of competency. Personnel Management, June, 37-41.

Ghafarian V. (1999). Managerial Competencies. Industrial Management Organization, Tehran, Iran.

Hellriegel, D., Jackson, S. E., \& Slocum, J. W. (2002). Management: A competency-based approach. South-Western: Thomson Learning.

Hitt, M. A., Ireland, R. D., \& Hoskisson, R. E. (2005). Strategic management: Competitiveness and globalization (6th ed.). Versailles, KY7 South-Western. 
Huselid, M. A. (1995). The impact of human resource management practices on turnover, productivity, and corporate financial performance. Academy of Management Journal, 38(3), 635-672.

Hwang .C.L and K. Yoon,.(1981). Multiple Attributes Decision Making Methods and Applications, spring, New York.

Lipiec, J. (2001). Human resources management perspective at the turn of the century. Public Personnel Management, 30(2), 137-146.

Liu, Y., Combs, J. G., Ketchen, D. J., \& Ireland R. D. (2007). The value of human resource management for organizational performance. Business Horizons, 50, 503-511.

Mansfield, R. (1999). What is competence all about. Competency, 6(3), 24-28.

Marlow, S. (2006). Human resource management in smaller firms: A contradiction in terms?. Human Resource Management Review, 16, 467-477.

Opricovic. S and Tzeng. G.H. (2003). Compromise solution by MCDM methods: a comparative analysis of VIKOR and TOPSIS, European Journal of Operational Research 156 (2) ,pp. 445-455.

Quinn, R. E., Faerman, S. R., Thompson, M. P., \& McGrath, M. (1996). Becoming a master manager: A competency framework. New York: John Wiley \& Sons.

Spencer, L. M., \& Spencer, S. M. (1993). Competence at work: Model for superior performance. Inc, New York: John Wiley \& Sons.

Schoonover, S. C., Schoonover, H., Nemerov, D., \& Ehly, C. (2000). Competency-based HR applications: Results of a comprehensive survey. Reports of the Arthur Andersen, Schoonover, SHRM, Virginia: Alexandria.

Selmer, J., \& Chiu, R. (2004). Required human resources competencies in the future: a framework for developing HR executives in Hong Kong. Journal of World Business, 39, 324-336.

Spencer, L., McClelland, D., \& Spencer, S. (1990). Competency assessment methods. Boston: Hay/McBer Research.

Sudsakorn, T., \& Swierczek, F. W. (2009). Management competencies: a comparative study between Thailand and Hong Kong. Journal of Management Development, 28(7), 569-580.

Thornton, G. C., \& Byham, W. C. (1982). Assessment centers and managerial performance. New York7 Academic Press. 
Turner, D., \& Crawford, M. (1994). Managing current and future competitive performers: The role of competency. In G. Hamel, \& A. Heene (Eds.), Competency-based competition: Strategic management series (pp. 241-254). Chichester, England: Wiley.

Wang, Y., Chin.,K. 2011, Fuzzy analytic hierarchy process: A logarithmic fuzzy preference Programming methodology, International Journal of Approximate Reasoning 52, 541-553.

Woodruffe, C. (1991). Competent by any other name. Personnel Management, September, $30-33$.

Wu, W. W., Lee, Y. T., \& Tzeng, G. H. (2005). Simplifying the manager competency model by using the rough set approach. In Dominik Slezak, JingTao Yao, James F. Peters, Wojciech Ziarko, \& Xiaohua Hu (Eds.), Rough sets, fuzzy sets, data mining, and granular computing. LNAI 3642 (Part II) (pp. 484-495).

Wu, W. W., \& Lee, Y. T. (2007). Developing global managers' competencies using the fuzzy DEMATEL method. Expert Systems with Applications, 32, 499-507.

Zarei Matin, H., Fathi, M. R., Karimi Zarchi, M., \& Azizollahi, S. (2011). The Application of Fuzzy TOPSIS Approach to Personnel Selection for Padir Company, Iran. Journal of management Research, 3(2), doi:10.5296/jmr.v3i2.663. 